\title{
The Effect of Hyperventilation on
}

\section{Distal Nephron Hydrogen Ion Secretion}

\author{
R. A. Giammarco, M. B. Goldstein, M. L. Halperin, and \\ B. J. STINEBAUGH
}

From the Department of Medicine, University of Toronto, Toronto M5S 1A8, Canada and Baylor College of Medicine, Houston, Texas 77025

A в S T R A C T This study was designed to determine the effect of acute hyperventilation on distal nephron hydrogen ion secretion. The blood $\mathrm{PcO}_{2}$ declined and stabilized rapidly when bicarbonate loaded rats were hyperventilated. In contrast, the urine $\mathrm{Pco}$ declined slowly, resulting in an early increase in the urine minus blood (U-B) $\mathrm{Pco}$ which could not be obliterated by carbonic anhydrase infusion. Within approximataely $50 \mathrm{~min}$, the $\mathrm{U}-\mathrm{B} \mathrm{PCO}_{2}$ in the hyperventilated and carbonic anhydrase infused rats approached zero. Consequently, equilibrium between collecting duct urine and arterial blood $\mathrm{PCO}_{2}$ was then presumed to exist. This provided the basis for the subsequent studies on a series of rats. The U-B Pcon decreased from a control of $22 \pm 1 \mathrm{~mm} \mathrm{Hg}$ (mean $\pm \mathrm{SEM}$ ) to $11 \pm 2 \mathrm{~mm} \mathrm{Hg}$ (mean $\pm \mathrm{SEM}$ ) with hypocapnia, and rose again to its control value when the blood $\mathrm{PCO}_{2}$ returned to prehyperventilation values. This decline in U-B Pcos with acute hyperventilation could not be attributed to changes in urine flow, phosphate, or bicarbonate excretion, suggesting, therefore, a decrease in distal nephron (probably collecting duct) hydrogen ion secretion with acute hyperventilation. Possible pitfalls in the interpretation of the U-B $\mathrm{PCO}_{2}$ are illustrated.

\section{INTRODUCTION}

The effect of hyperventilation on the rate of hydrogen ion secretion in the terminal segments of the nephron has not been elucidated. Stanbury and Thomson (1) suggested that the electrolyte excretion patterns observed during hypocapnia might be due to inhibition of hydrogen ion secretion in the kidney. Micropuncture studies have shown that hyperventilation decreases hydrogen ion secretion in the proximal and distal convoluted tubules (2), but information about the response of the collecting duct to this maneuver is not available.

\footnotetext{
Received for publication 20 October 1975 and in revised form 18 February 1976.
}

The collecting duct is probably the most important segment of the nephron for achieving the minimum urine $\mathrm{pH}$ and thereby for augmenting acid excretion. In addition, the collecting duct has a major regulatory role in homeostasis under a variety of conditions (3).

In the present study, we have attempted to characterize the effect of hyperventilation on the distal nephron. To accomplish this, we have estimated distal nephron hydrogen ion secretion by utilizing the urine minus blood (U-B) ${ }^{1} \mathrm{PcO}_{2}$ gradient (4). The U-B $\mathrm{PCO}_{2}$ decreased during hyperventilation. This result cannot be explained by changes in urinary volume, bicarbonate, or buffer excretion. We propose that hyperventilation results in a reduction in distal nephron hydrogen ion secretion, presumably in the collecting duct.

\section{METHODS}

Experimental protocol. Male Wistar rats $(250-300 \mathrm{~g})$, obtained from Woodlyn Farms, Guelph Ontario, were allowed free access to food (Purina Lab Chow) and water before the experiment. Sodium bicarbonate, $(20 \mathrm{~g} / 1)$ and glucose $(50 \mathrm{~g} / 1)$ were added to the drinking water 2 days before the experiment to facilitate alkalinization of the urine. Rats were anesthetized with inactin, $100 \mathrm{mg} / \mathrm{kg}$ intraperitoneally. Intravenous infusions were administered into the jugular vein. Blood pressure was monitored by a femoral artery catheter connected to a mercury manometer. Blood samples were collected from the femoral artery into heparinized capillary tubes. The urine for $\mathrm{pH}$ and $\mathrm{PCO}_{2}$ was collected anaerobically into capillary tubes via a suprapubic catheter in the bladder. $\mathrm{pH}$ and $\mathrm{PCO}_{2}$ determinations were performed immediately after the collection as previously described (5). Urine for flow rate and all other parameters was collected into pretared vessels.

After induction of anaesthesia, $0.3 \mathrm{M}$ sodium bicarbonate was infused at a rate of $100 \mu \mathrm{l} / \mathrm{min}$ throughout the experiment. When the urine $\mathrm{pH}$ and $\mathrm{PCO}_{2}$ remained constant for three consecutive periods, a steady state was assumed to exist and blood was collected for $\mathrm{pH}$ and $\mathrm{PCO}_{2}$. After the

\footnotetext{
${ }^{1}$ Abbreviations used in this paper: GFR, glomerular fil-
} tration rate; U-B, urine minus blood. 


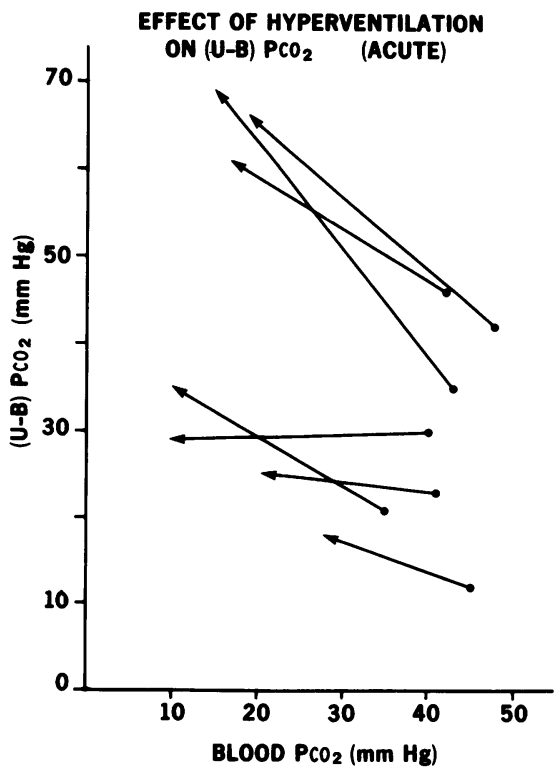

Figure 1 Each line represents values from a single rat. During control ventilation the U-B $\mathrm{PCO}_{2}$ was $30 \pm 4.6 \mathrm{~mm}$ $\mathrm{Hg}$ (mean $\pm \mathrm{SEM}$ ). With $5-15 \mathrm{~min}$ of acute hyperventilation, the U-B $\mathrm{PCO}_{2}$ rose to $43.3 \pm 8.1 \mathrm{~mm} \mathrm{Hg}$ (mean $\pm \mathrm{SEM}$ ) giving an increased $\Delta \mathrm{U}-\mathrm{B} \mathrm{PCO}_{2}$ of $13.7 \pm 4.6 \mathrm{~mm} \mathrm{Hg}, P$ $<0.025$. -Before hyperventilation, $\Delta$-Acute (5-15 $\mathrm{min})$ hyperventilation.

control period, hyperventilation was induced with a mechanical respirator (Phipps and Bird small animal respirator, model no 7088-600, Phipps and Bird Inc., Richmond, Va.). In the experiments reported in Figs. 1-3, samples were obtained after the blood $\mathrm{PcO}_{2}$ had declined to a steadystate value (blood $\mathrm{PCO}_{2}$ in two consecutive samples stable within $3-5 \mathrm{~mm} \mathrm{Hg}$ ). In the experiments reported in Tables I and II, by contrast, samples were collected after the urine $\mathrm{PCO}_{2}$ had remained constant for three consecutive periods. The animals were hyperventilated for approximately $90 \mathrm{~min}$ before the experimental specimens were taken. The respirator was then disconnected and the measurements were repeated after 15-30 min of spontaneous ventilation. If the blood $\mathrm{PCO}_{2}$ remained low, the animal was placed in a covered box where the inspired gas contained humidified $5 \%$ $\mathrm{CO}_{2} ; 95 \% \mathrm{O}_{2}$. Two rats hyperventilated spontaneously during the first period. In these animals steady-state values were obtained during hyperventilation and then normocapnia was induced by exposing them to the $5 \% \quad \mathrm{CO}_{2} ; 95 \% \quad \mathrm{O}_{2}$ gas mixture. Subsequently, they were removed from the box and allowed to resume spontaneous hyperventilation. Since the results were similar with both methods of hyperventilation, the data from both groups were combined.

Carbonic anhydrase was injected intravenously as a $2-\mathbf{m g}$ bolus followed by a continuous infusion at a rate of 20 $\mu \mathrm{g} / \mathrm{min}$. Glomerular filtration rates (GFR) were measured with tritium labeled inulin using a $5-\mu \mathrm{Ci}$ priming dose followed by a sustaining dose of $6 \mu \mathrm{Ci} / \mathrm{h}$.

Analytical Methods. The blood and urine samples for $\mathrm{pH}$ and $\mathrm{PCO}_{2}$ were measured on a Radiometer model PHM72 digital acid base analyzer. Urine bicarbonate concentrations were calculated from the $\mathrm{pH}$ and $\mathrm{PCO}_{2}$ using a $\mathrm{pK}$ as determined from the formula: $\mathrm{pK}=6.33-0.5 \vee \bar{\mu}(6)$ and a solubility coefficient of 0.0309 . Sodium and potassium were measured by flame photometry as previously described (4). Phosphorus was measured by a modified method for the photoelectric colorimeter (7). Organic anions were measured by the titrimetric method of Chan (8). Tritium was measured on a Beckman LS 230 liquid scintillation counter (Beckman Instruments, Inc., Cedar Grove, N. J.) as previously described (5). Statistical analyses were performed by using a $t$ test on paired observations.

Materials and supplies. All chemicals were of analytical grade. Tritium labeled inulin was obtained from New England Nuclear, Boston, Mass.; inactin from Henley and Co., Inc., New York; gas mixtures from Gas Dynamics, Toronto, Ontario; carbonic anhydrase from Sigma Chemical Co., St. Louis, Mo.; and reference buffers from Radiometer Co., Copenhagen, Denmark.

\section{RESULTS}

With acute hyperventilation, the blood $\mathrm{PcO}_{2}$ decreased rapidly and stabilized while the urine $\mathrm{PCO}_{2}$ declined more slowly. This resulted in an immediate rise in the U-B $\mathrm{PcO}_{2}$ of $13.7 \pm 4.6 \mathrm{~mm} \mathrm{Hg}, P<0.025$ (control U-B $\mathrm{PcO}_{2}$ was $30 \pm 4.6 \mathrm{~mm} \mathrm{Hg}$, acute hyperventilation U-B $\mathrm{Pco}_{2}$ was $43.3 \pm 8.1 \mathrm{~mm} \mathrm{Hg}$, mean $\pm \mathrm{SEM}, n=7$ ) (Fig. 1). To evaluate the possibility that the initial increase in the U-B Pcos was due to the failure of the arterial blood to reflect the medullary $\mathrm{Pco}_{2}$, or to mixing of urines with a higher and lower $\mathrm{Pco}_{2}$, carbonic anhydrase was infused into control and acutely hyperventilated rats. These results are shown in Fig. 2 and demonstrate that the U-B Pcos gradient was immediately abolished in the control rats $(1 \pm 0.2 \mathrm{~mm} \mathrm{Hg})(n=4)$ but not in the acutely hyperventilated rats. Therefore, the initial increase in the U-B Pcos could not be attributed to a distal nephron mechanism involving delayed dehydration

\section{EFFECT OF CARBONIC ANHYDRASE INFUSION ON (U-B) $\mathrm{PCO}_{2}$ AFTER HYPERVENTILATION}

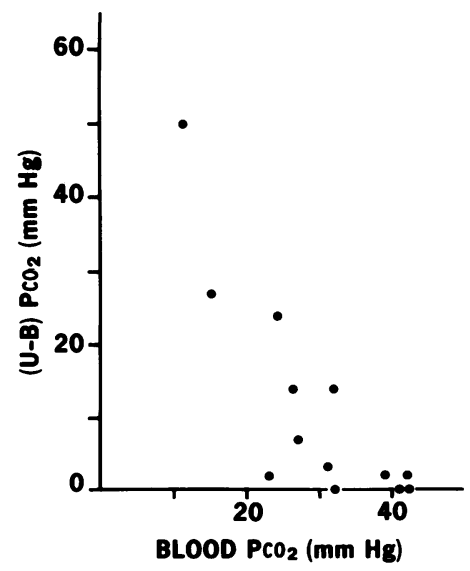

FIgURE 2 Each dot represents an individual rat. In the nonhyperventilated rats infused with carbonic anhydrase, the U-B $\mathrm{PCO}_{2}$ gradient was not significantly different from zero $(1 \pm 0.2) \mathrm{mm} \mathrm{Hg}$ (mean $\pm S E M)$. In rats with a blood $\mathrm{PCO}_{2}$ $<30 \mathrm{~mm} \mathrm{Hg}$ and infused with carbonic anhydrase, the $\mathrm{U}-\mathrm{B} \mathrm{PCO}_{2}$ ranged from 2 to $50 \mathrm{~mm} \mathrm{Hg}$ when measured after $5-15$ min of hyperventilation. 
TABLE I

Effect of Hyperventilation on $U-B \quad \mathrm{PCO}_{2}$

\begin{tabular}{|c|c|c|c|c|c|c|c|c|}
\hline \multirow[b]{2}{*}{ Rat } & \multicolumn{2}{|c|}{ Normocapnia } & \multicolumn{2}{|c|}{ Hypocapnia } & \multicolumn{2}{|c|}{ Normocapnia } & \multicolumn{2}{|c|}{ Hypocapnia } \\
\hline & $\mathrm{B} \mathrm{PCO}_{2}$ & U-B $\mathrm{PCO}_{2}$ & B $\mathrm{PCO}_{2}$ & U-B $\mathrm{PcO}_{2}$ & B Pco2 & U-B Pco, & B Pcon & U-B $\mathrm{PcO}_{2}$ \\
\hline & \multicolumn{2}{|c|}{$m m \mathrm{Hg}$} & \multicolumn{2}{|c|}{$m m \mathrm{Hg}$} & \multicolumn{2}{|c|}{$\mathrm{mm} \mathrm{Hg}$} & \multicolumn{2}{|c|}{$m m \mathrm{Hg}$} \\
\hline 1 & 32 & 19 & 25 & 6 & 33 & 18 & & \\
\hline 2 & 32 & 20 & 19 & 9 & 30 & 18 & & \\
\hline 3 & 34 & 24 & 28 & 10 & 35 & 24 & & \\
\hline 4 & 40 & 21 & 27 & 4 & 39 & 22 & 26 & 9 \\
\hline 5 & & & $29^{*}$ & 16 & 40 & 25 & 26 & 16 \\
\hline 6 & & & $28^{*}$ & 17 & 36 & 24 & 28 & 17 \\
\hline
\end{tabular}

B, blood.

* These animals were hyperventilating spontaneously and therefore the initial period was treated as a hypnocapnia one. Each value represents the mean of the values in three consecutive periods.

of carbonic acid, that is to an increase in distal nephron hydrogen ion secretion. In a separate group of rats, carbonic anhydrase was infused for $50 \mathrm{~min}$ after acute induction of hyperventilation. The U-B $\mathrm{PCO}_{2}$ in hyperventilating rats was $32 \pm 4 \mathrm{~mm} \mathrm{Hg}$ (mean $\pm S E M, n=6$ ), $10 \mathrm{~min}$ after carbonic anhydrase infusion but decreased virtually to zero after approximately $50 \mathrm{~min}(2.5 \pm 1.0$ $\mathrm{mm} \mathrm{Hg}, n=6$ ) when equilibrium between arterial blood and renal medulla was assumed to exist. Therefore, the control U-B $\mathrm{PcO}_{2}$ values were compared to values obtained after at least $50 \mathrm{~min}$ of hyperventilation in subsequent studies. As shown in Fig. 3, the U-B Pcos gradient decreased significantly $(P<0.01)$ as a result of steady-state hyperventilation. Furthermore, the results reported in Table I demonstrate that $\mathrm{U}-\mathrm{B} \mathrm{PCO}_{2}$ gradient returned to control values when the blood $\mathrm{PcO}_{2}$ returned to prehypocapnia values.

Other factors known to affect the U-B $\mathrm{PcO}_{2}$ are the rate of buffer excretion, urine flow, and bicarbonate excretion. There was no significant fall in the urine phos- phate excretion as a result of hyperventilation when the control and experimental periods were compared by the paired $t$-test (Table II). The analysis of paired data, however, reveal that there were significant decreases in both urinary flow rate and bicarbonate excretion rate during hyperventilation (Table II). GFR's were measured in three experiments and the results were similar in both states $(2.20 \pm 0.5$ vs. $2.01 \pm 0.6 \mathrm{ml} / \mathrm{min}$ in normal and hyperventilated rats, respectively). Calculated bicarbonate reabsorption rates in these experiments were $33.2 \mathrm{meq} / 1 \mathrm{GFR}$ in the control period and $27.5 \mathrm{meq} / 1$ GFR after $60 \mathrm{~min}$ of hyperventilation.

The U-B Pcos was decreased during hypocapnia when the results were compared at similar rates of urine flow, and bicarbonate, and phosphate excretion (Table III). For these data, a group of bicarbonate loaded rats with bicarbonate excretion rates between 1.5 and $8.0 \mu \mathrm{eq} / \mathrm{min}$ and phosphate excretion rates between 0.5 and $1.2 \mu \mathrm{mol} /$ min was chosen for the normocapneic group for comparison with the hyperventilation data. (Methods for

TABLE II

Effect of Hyperventilation on the $U-B \quad P \mathrm{CO}_{2}$ and on Parameters Influencing $U-B \quad \mathrm{PCO}_{2}$

\begin{tabular}{|c|c|c|c|c|c|c|c|c|c|c|c|}
\hline & \multirow{2}{*}{\multicolumn{11}{|c|}{ Summary of data }} \\
\hline & & & & \multicolumn{7}{|c|}{ Urine } & \multirow{2}{*}{$\frac{\mathrm{U}-\mathrm{B}}{\mathrm{PCO}_{2}}$} \\
\hline & $\mathrm{pH}$ & $\mathrm{PCO}_{2}$ & $\mathrm{Hco}_{2}$ & $\mathrm{pH}$ & $\mathrm{PcO}_{2}$ & {$\left[\mathrm{HCO}_{2}{ }^{-}\right]$} & $\mathrm{HCO}_{3}^{-}$ & Phosphate & $\begin{array}{l}\text { Organic } \\
\text { anions }\end{array}$ & Flow & \\
\hline & & $m m \mathrm{Hg}$ & meq/liter & & $m m \mathrm{Hg}$ & meq/liter & $\mu e q / \min$ & $\mu \mathrm{mol} / \mathrm{min}$ & $\mu e q / \min$ & $\mu l / \min$ & $m m H_{g}$ \\
\hline \multirow[t]{2}{*}{ Control } & 7.58 & 36 & 33 & 7.81 & 58 & 104.8 & 11.2 & 0.96 & 14.1 & 120 & 22 \\
\hline & \pm 0.04 & \pm 1 & \pm 2.2 & \pm 0.06 & \pm 2 & \pm 19.6 & \pm 2.2 & \pm 0.23 & \pm 2.5 & \pm 31 & \pm 1 \\
\hline \multirow[t]{2}{*}{ Hyperventilation } & 7.68* & $26 \ddagger$ & 30 & 7.84 & $37 \ddagger$ & 71.9 & $4.0^{*}$ & 0.72 & $8.0 *$ & $72 \ddagger$ & $11 \ddagger$ \\
\hline & \pm 0.02 & \pm 1 & \pm 1.3 & \pm 0.07 & \pm 3 & \pm 9.0 & \pm 0.5 & \pm 0.14 & \pm 1.5 & \pm 16 & \pm 2 \\
\hline
\end{tabular}

These values represent the means and standard error of the means for control and hyperventilation data on animals from Table $I$.

$* P<0.05$ for paired observations.

$\ddagger P<0.01$. 


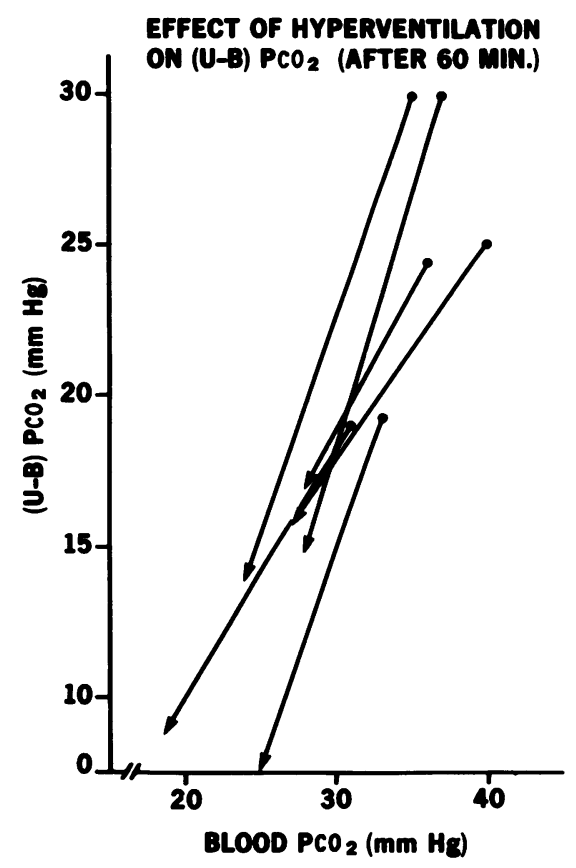

Figure 3 Each line represents values from a single rat. During control ventilation, the U-B $\mathrm{PcO}_{2}$ was $(22 \pm 1) \mathrm{mm}$ $\mathrm{Hg}($ mean $\pm \mathrm{SEM}),(n=7)$. With steady state $60 \mathrm{~min}$ hyperventilation the U-B $\mathrm{PcO}_{2}$ fell to $(11 \pm 2) \mathrm{mm} \mathrm{Hg}$ (mean \pm SEM).

preparation of animals, infusion protocols, and sample analyses were identical). The mean bicarbonate excretion rates were $4.7 \pm 0.6$ and $4.0 \pm 0.5 \mu \mathrm{eq} / \mathrm{min}$, urine flow rates were $52 \pm 10$ and $72 \pm 16 \mu \mathrm{l} / \mathrm{min}$ and phosphate excretion rates were $0.80 \pm 0.08$ and $0.72 \pm 0.14 \mu \mathrm{mol} / \mathrm{min}$, respectively, in the normal and hyperventilating rats. The U-B Pcos was $26.2 \pm 1.5 \mathrm{~mm} \mathrm{Hg}$ in the control group and was $11 \pm 2 \mathrm{~mm} \mathrm{Hg}$ in the hypocapneic group.

\section{DISCUSSION}

The U-B Pcon gradient is a qualitative index of distal nephron hydrogen ion secretion. The physiologic basis for this assumption has been discussed previously (4). Briefly, carbonic acid is formed in the lumen of the distal nephron from the interaction of secreted hydrogen ions with the lumenal bicarbonate. Since carbonic anhydrase activity is virtually absent in this area of the nephron (9), the dehydration of carbonic acid is delayed until it reaches the lower urinary tract, where, because of unfavorable surface: volume relationships, little $\mathrm{CO}_{2}$ is reabsorbed. It has been shown (10) that blood $\mathrm{PCO}_{2}$ is a reasonable estimate of renal vasa recta $\mathrm{PCO}_{2}$ in rats infused with sodium bicarbonate. Therefore, the U-B Pcoa is an index of distal nephron net hydrogen ion secretion.

Several criteria must be met before one can use the U-B PcO2 to assess distal nephron hydrogen ion secre- tion. The U-B Pco2 must be measured during steadystate conditions. As shown in Fig. 1, the U-B Pcon gradient was increased after acute hyperventilation. This would indicate an increased distal nephron hydrogen ion secretion only if the blood $\mathrm{PCO}_{2}$ accurately reflected renal medullary $\mathrm{Pcos}$. In acute hypocapnia this may not be the case if there is inadequate time for equilibration. The U-B Pcos would overestimate distal nephron hydrogen ion secretion in this circumstance. The U-B $\mathrm{PcO}_{2}$ could also overestimate distal hydrogen ion secretion if the collection contained urine with a higher $\mathrm{Pco}_{2}$ formed before hyperventilation.

The elevation in the urine minus vasa recta $\mathrm{Pco}_{2}$ due to distal nephron hydrogen ion secretion is abolished by carbonic anhydrase infusion (11). Carbonic anhydrase infused into acutely hyperventilated rats resulted in a fall in the U-B $\mathrm{PCO}_{2}$ but not to levels which approximated

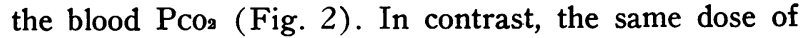
carbonic anhydrase caused the urine $\mathrm{PcO}_{2}$ to virtually equal the blood $\mathrm{PCO}_{2}$ in the normocapniac animals, confirming the results of others $(9,11,12)$. The U-B Pco2 approached zero after $50 \mathrm{~min}$ in acutely hyperventilated rats infused with carbonic anhydrase, indicating that a steady state had been achieved between arterial blood and collecting duct urine by this time. Detailed studies were then carried out to study the effects of hyperventilation on U-B Pcos after allowing 50 min equilibration time in order to achieve this steady state. There was a significant reduction in the U-B $\mathrm{PCO}_{2}$ gradient during hypocapnia which returned to control values with cessation of hyperventilation (Table I).

Assuming steady-state conditions, the degree of elevation of the $\mathrm{U}-\mathrm{B} \mathrm{PcO}_{2}$ is influenced by the interplay of several factors in addition to distal hydrogen ion secretion. These include rates of buffer excretion, urine

TABLE III

Effect of Hyperventilation on the U-B $\mathrm{PCO}_{2}$ at Matched Rates of Urine Flow Phosphate and

Bicarbonate Excretion

\begin{tabular}{lcc}
\hline & Normocapnia & Hypocapnia \\
\hline Blood $\mathrm{PCO}_{2}, \mathrm{~mm} \mathrm{Hg}$ & $40.7 \pm 1.7$ & $26 \pm 1^{*}$ \\
Bicarbonate excretion, $\mu \mathrm{eq} / \mathrm{min}$ & $4.7 \pm 0.6$ & $4.0 \pm 0.5$ \\
Phosphate excretion, $\mu \mathrm{mol} / \mathrm{min}$ & $0.80 \pm 0.08$ & $0.72 \pm 0.14$ \\
Urine flow rate, $\mu \mathrm{l} / \mathrm{min}$ & $52 \pm 10$ & $72 \pm 16$ \\
(U-B) $\mathrm{PCO}_{2}, \mathrm{~mm} \mathrm{Hg}$ & $26.2 \pm 1.5$ & $11 \pm 2^{*}$
\end{tabular}

The animals selected in the normocapnia group $(n=16)$ were those in which the urine flow rate phosphate excretion rate, and bicarbonate excretion rate were comparable to those observed in the hypocapnia group $(n=6)$ reported in Table II. The methods for preparation of animals, infusion protocols, and sample analyses were identical for both groups. Results are reported as mean $\pm \mathrm{SEM}$.

$* P<0.01$. 
flow, and bicarbonate delivery. The major urine buffer is phosphate. There is a direct correlation between the U-B PCO2 and the urine phosphate concentration (13). Phosphate infusion elevates the urine $\mathrm{PcO}_{2}$, presumably by delaying the dehydration of carbonic acid (14). There was no decline in urine phosphate concentration or excretion rates, however, during acute hyperventilation (Table II). Therefore, alterations in urine phosphate excretion are excluded as an important factor in our studies. Urine flow rate is another factor requiring consideration. Reid and Hills demonstrated that the urine $\mathrm{Pco}_{2}$ varies inversely with urine flow (15). In these studies, both the U-B Pcoa and urine flow rate fell with hyperventilation (Table I). Therefore, these results cannot be attributed to the changes in flow rate. Bicarbonate excretion rate can also influence the urine $\mathrm{Pco}$ (16). Although the urine $\mathrm{pH}$ exceeded 7.55 in our studies, the urine bicarbonate excretion rates decreased with hyperventilation (Table II). We therefore examined the U-B Pcos at comparable rates of bicarbonate excretion in both normo- and hypocapnia (Table III). The U-B Pcos was $26.2 \pm 1.5 \mathrm{~mm} \mathrm{Hg}$ during normocapnia when the bicarbonate excretion rate was $4.7 \pm 0.6 \mu \mathrm{eq} /$ min whereas the U-B $\mathrm{Pco}_{2}$ was significantly reduced to $11 \pm 2 \mathrm{~mm} \mathrm{Hg}$ when the blood $\mathrm{PCO}_{2}$ was $28 \pm 1 \mathrm{~mm} \mathrm{Hg}$ and bicarbonate excretion $4.0 \pm 0.5 \mu \mathrm{eq} / \mathrm{min}$. Urine flow rate and phosphate excretion rates were comparable between groups. Furthermore, examination of the data of Thompson and Barrett (17) demonstrates that when the bicarbonate excretion rate is acutely reduced by constriction of the aorta in bicarbonate loaded animals, the U-B Pcon did not decrease. Similar results were obtained in our laboratory when the bicarbonate excretion was decreased by acute unilateral ureteral constriction or by sodium nitroprusside infusion (unpublished observations). Thus, it appears unlikely that the hypocapniainduced fall in U-B Pcos was caused by the reduced rate of bicarbonate excretion.

Another possible cause for the decreased U-B Pcos during hyperventilation is an increased rate of reabsorption of organic acids that were titrated in the distal nephron (18). This is unlikely in these experiments because the rate of organic anion excretion did not increase in bicarbonate-infused rats with superimposed hyperventilation.

The exact nephron segment responsible for the decreased U-B Pcos noted in our studies cannot be precisely determined. However, as the transit time from the distal tubule to renal pelvis is approximately $20 \mathrm{~s}$, (19) and the $\mathrm{H}_{2} \mathrm{CO}_{3}$ dehydration time is quite rapid in urine of low buffer capability (20), we consider it unlikely that the U-B Pcos originates from areas other than the terminal collecting duct (18). It is conceivable that a reduction in the U-B $\mathrm{PCO}_{2}$ during hyperventilation, rather than being due to decreased hydrogen ion secretion, might occur as the consequence of carbonic acid reabsorption in the collecting duct or to an increased rate of its dehydration within the lumen of this nephron segment. We feel that these latter possibilities are less likely and therefore interpret our data to indicate that the collecting duct responds to hypocapnia with a decrease in hydrogen ion secretion. If one assumes a semi-quantitative dimension for the U-B $\mathrm{PCO}_{2}$, the data presented would suggest that the largest proportional decrease in hydrogen ion secretion during hyperventilation occurs in the collecting duct. That is, the U-B $\mathrm{PCO}_{2}$ decreased from $22 \pm 1$ to $11 \pm 2$, a $50 \%$ decline while the total bicarbonate reabsorption decreased only $17 \%$ from 33.2 to $27.5 \mathrm{mM} / 1 \mathrm{GFR}$. This type of analysis, however, is potentially misleading in view of the lack of information regarding the quantitative aspect of the relationship between the collecting duct secretion and the U-B $\mathrm{Pco}_{2}$.

Previous investigators have provided indirect evidence that distal hydrogen ion secretion might be reduced in hypocapnia. Stanbury and Thomson (1) found an increased urine sodium and potassium excretion in respiratory alkalosis and suggested that this might reflect decreased distal nephron hydrogen ion secretion. Gennari et al. (21) demonstrated that net acid excretion was decreased in dogs with chronic hyperventilation. Malnic et al. (22) demonstrated in micropuncture studies that hypocapnia in rats reduced fractional and absolute bicarbonate reabsorption in both the proximal and distal tubules. They also note that hyperventilation reduced the dysequilibrium $\mathrm{pH}$ in the distal convoluted tubule of bicarbonate-infused rats. Their results strongly suggest a decrease in distal tubular hydrogen ion secretion.

Two major implications result from our studies. One is that the U-B $\mathrm{PcO}_{2}$ provides a powerful tool to assess collecting duct hydrogen ion secretion in vivo provided the critical criteria are satisfied. In addition to controlling the excretion rates of phosphate, bicarbonate, and water, one must also control for the blood $\mathrm{PcO}_{2}$ and ensure that measurements are made under steady state conditions. The other is that acute hyperventilation reduces collecting duct hydrogen ion secretion. This might be the basis for the reduced net acid excretion observed with more prolonged hypocapnia, leading to the greater fall in blood bicarbonate concentration associated with chronic hypocapnia $(21,23-25)$. In conclusion, we interpret our data to indicate that acute steady-state hyperventilation causes a decrease in distal nephron (presumably collecting duct) hydrogen ion secretion.

\section{ACKNOWLEDGMENTS}

This work was supported by grants from the Medical Research Council of Canada (MT 3363 and MA 5623), the Atkinson Foundation, the Department of Medicine, University of Toronto and the S.t. Michael's Hospital Research Society-Herbert M. Follows Memorial Fund. The authors 
are grateful to Dr. Janet Roscoe and Dr. Vern MacMillan for helpful advice and discussion. The technical assistance of Ms. Barbara Green and Ms. Brenda Halperin are gratefully acknowledged.

\section{REFERENCES}

1. Stanbury, S. W., and A. E. Thomson. 1952. The renal response to respiratory alkalosis. Clin. Sci. (Oxf.) 11: 357-374.

2. Vieira, F. L., and G. Malnic. 1968. Hydrogen ion secretion by rat renal cortical tubules as studied by an antimony microelectrode. Am. J. Physiol. 214: 710-718.

3. Stein, J. H., and H. J. Reineck. 1974. The role of the collecting duct in the regulation of excretion of sodium and other electrolytes. Kidney Int. 6: 1-9.

4. Halperin, M. L., M. B. Goldstein, A. Haig, M. D. Johnson, and B. J. Stinebaugh. 1974. Studies on the pathogenesis of type I (distal) renal tubular acidosis as revealed by the urinary $\mathrm{PCO}_{2}$ tensions. J. Clin. Invest. 53: 669-677.

5. Roscoe, J. M., M. B. Goldstein, M. L. Halperin, D. R. Wilson, and B. J. Stinebaugh. 1976. Lithium induced impairment of urine acidification. Kidney Int. 9: 344-350.

6. Hastings, A. B., and J. Sendroy, Jr. 1925. The effect of variation in ionic strength on the apparent first and second dissociation constants of carbonic acid. J. Biol. Chem. 65: 445-455.

7. Gomori, G. 1942. A modification of the colorimetric phosphorus determination for use with the photoelectric colorimeter. J. Lab. Clin. Med. 27: 955-960.

8. Chan, James, C. M. 1972. Urinary organic anions: clinical significance and evaluation of a method for determination and preservation. Clin. Biochem. 5: 182-185.

9. Rector, F. C., Jr., D. W. Seldin, A. D. Roberts, Jr., and J. S. Smith. 1960. The role of plasma $\mathrm{CO}_{2}$ tension and carbonic anhydrase activity in the renal reabsorption of bicarbonate. J. Clin. Invest. 39: 1706-1721.

10. Uhlich, E., C. A. Baldamus, and K. J. Ullrich. 1968. Verhalten von $\mathrm{CO}_{2}$-Druck und bicarbonat im Gegenstromsystem des Nierenmarks. Pfluegers Arch. Eur. J. Physiol. 303: 31-48.

11. Ochwadt, B. K., and R. F. Pitts. 1956. Effects of intravenous infusion of carbonic anhydrase on carbon dioxide tension of alkaline urine. Am. J. Physiol. 185: $426-429$.

12. Rector, F. C., Jr., N. W. Carter, and D. W. Seldin. 1965. The mechanism of bicarbonate reabsorption in the proximal and distal tubules of the kidney. J. Clin. Invest. 44 : 278-290.

13. Kennedy, T. J., Jr., J. Orloff, and R. W. Berliner. 1952 Significance of carbon dioxide tension in the urine. $\mathrm{Am}$. J. Physiol. 169 : 596-608.

14. Stinebaugh, B. J., F. X. Schloeder, E. Ghafary, W. N. Suki, M. B. Goldstein, and M. L. Halperin. 1975. Mechanism of elevation of urinary $\mathrm{pCO}_{2}$ by neutral phosphate $\left(\mathrm{PO}_{4}{ }^{\circ}\right)$. Clin. Res. 23: 376A. (Abstr.)

15. Reid, E. L., and A. G. Hills. 1965. Diffusion of carbon dioxide out of the distal nephron in man during antidiuresis. Clin. Sci. (Oxf.) 28: 15-28.

16. Portwood, R. M., D. W. Seldin, F. C. Rector, Jr., and R. Cade. 1959. The relation of urinary $\mathrm{CO}_{2}$ tension to bicarbonate excretion. J. Clin. Invest. 38: 770-776.

17. Thompson, D. D., and M. J. Barrett. 1954. Renal reabsorption of bicarbonate. Am. J. Physiol. 176: 201206.

18. Brodsky, W. A., J. F. Miley, J. T. Kaim, and N. P. Shah. 1958. Characteristics of acidic urine after loading with weak organic acids in dogs. Current concepts on renal mechanisms of acidification in relation to data on $\mathrm{CO}_{2}$ tension. Am. J. Physiol. 193: 108-122.

19. Morel, F., M. Mylle, and C. W. Gottschalk. 1965. Tracer microinjection studies of effect of $\mathrm{ADH}$ on renal tubular diffusion of water. Am. J. Physiol. 209: 179-187.

20. Kennedy, T. J., Jr., M. Eden, and R. W. Berliner. 1957 Interpretation of urine $\mathrm{CO}_{2}$ tension. Fed. Proc. 16: 72. (Abstr.)

21. Gennari, F. J., M. B. Goldstein, and W. B. Schwartz. 1972. The nature of the renal adaptation to chronic hypocapnia. J. Clin. Invest. $51: .1722-1730$

22. Malnic, G., M. de Mello Aires, and G. Giebisch. 1972. Micropuncture study of renal tubular hydrogen ion transport in the rat. Am. J. Physiol. 222: 147-158.

23. Barker, E. S., R. B. Singer, J. R. Elkinton, and J. K. Clark. 1957. The renal response in man to acute experimental respiratory alkalosis and acidosis. J. Clin. Invest. 36: 515-529.

24. Elkinton, J. R., R. B. Singer, E. S. Barker, and J. K. Clark. 1955. Effects in man of acute experimental respiratory alkalosis and acidosis on ionic transfers in the total body fluids. J. Clin. Invest. 34: 1671-1690.

25. Arbus, G. S., L. A. Hebert, P. R. Levesque, B. E. Etsten, and W. B. Schwartz. 1969. Characterization and clinical application of the "significance band" for acute respiratory alkalosis. N. Engl. J. Med. 280: 117-123. 